\title{
Editorial
}

\section{Sustainable Wastewater Treatment Systems (2018-2019)}

\author{
José Alberto Herrera Melián
}

Department of Chemistry, i-Unat (Institute of Environmental Studies and Natural Resources) University of Las Palmas de Gran Canaria, 35017 Las Palmas de Gran Canaria, Spain; josealberto.herrera@ulpgc.es; Tel.: +34-928-45-44-38

Received: 19 February 2020; Accepted: 21 February 2020; Published: 3 March 2020

check for updates

\begin{abstract}
An important part of the environmental degradation suffered by the planet is caused by the discharge of untreated or poorly treated wastewater. Industrial, urban, and agricultural wastewater contain many different types of pollutants such as biodegradable and nonbiodegradable organic matter, suspended solids, turbidity, nutrients, heavy metals, pesticides, pathogens, etc. All of these pose a threat to the environment and human health, so the selected treatment techniques must be adapted to their nature in order to optimize their removal. In addition to efficiency, wastewater treatment methods must be sustainable, not only from an environmental point of view, but also economically and ethically. As a result, no technological dependence should be generated in less developed countries or communities. Therefore, this Special Issue deals with improvements in various aspects of wastewater treatment including different aspects of water treatment such as the development of mathematical models, the application of life cycle techniques, or the experimental optimization of wastewater treatment methods. Thirteen articles were accepted covering some of the most relevant fields of wastewater treatment: activated sludge, nanoparticle treatment, constructed wetlands, energy-water nexus, nutrient recovery, eco-friendly sorbents, and reverse osmosis.
\end{abstract}

Keywords: water treatment; activated sludge; modeling; constructed wetland; advanced oxidation techniques; reverse osmosis; sorbents

Historically, water scarcity has been a major problem in many regions of the world. However, accessibility to water of sufficient quality is becoming an increasingly serious problem, mainly due to the pollution of aquifers and coastal areas, climate change, and overpopulation (Nguvava et al. [1], Ziadi et al. [2], Zhou et al. [3]).

Natural waters, and to a greater extent, sewage, must be treated before use, reuse, or being discharged. There are many pollutants that compromise water quality, and affect both the human being and the natural environment. Some of the most important threats come from industrial wastewater due to the toxicity of heavy metals, persistent organic compounds, etc. (Tayeb et al. [4]) However, urban wastewater, apparently easily treated by well-established methods for decades, is generating an increase in eutrophication events with direct consequences such as massive deaths of aquatic organisms, biodiversity reduction, red tides, etc. For example, the number of anoxic or sub-toxic zones in coastal waters has grown exponentially since 1960, with more than 400 hypoxic zones being reported worldwide (Diaz and Rosenberg [5]). The presence of pathogens (viruses, bacteria, and parasites) and their elimination remains an essential part in the treatment of wastewater (Chaukura et al. [6]). Hormonal disruptors are another of the many groups of pollutants that pose a health risk of unforeseeable consequences to humans and animals. These include a huge variety of substances including drugs, pesticides, additives of plastic products, bleaching agents, cleaning agents, etc. (Alvarez-Ruiz and Picó [7]). 
The current environmental situation of the planet also requires that the methods of water treatment, like any other human activity, are sustainable, but what does sustainable mean? Many times, we think about environmental sustainability exclusively and forget that sustainability, as understood by the United Nations in its 17 Sustainable Development Goals, is much more than that, since it includes economics and ethical-social aspects such as gender equality or the eradication of poverty for all (United Nations [8]).

Water treatment methods include a wide variety of techniques of a different nature, ranging from physical methods such as dissolved air flotation or membrane techniques to chemical methods such as the advanced oxidation techniques and the great variety of biological methods (Holkar et al. [9]). Within this last group, the low-cost, decentralized, or ecological techniques such as lagoons, constructed wetlands, trickling filters, or biodiscs have undergone a remarkable development (Guedes-Alonso et al. [10]).

The objective of this Special Issue "Sustainable Wastewater Treatment Systems" has been to review the state-of-the-art of the latest advances in water management with an particular focus on sustainable methods of disinfection, grey water, constructed wetlands, ponds, membranes, reclaimed wastewater reuse, etc. Many submissions have been received with significant contributions for the main topics of interest in our Special Issue. However, only 13 high-quality papers were accepted after strict and rigorous review. In particular, these accepted papers mainly focused on various perspectives such as innovative applications and research covering the removal of nanoparticles, constructed wetlands, microbial aspects of activated sludge, adaptation to climate change in water-energy coupling, nutrient recovery from wastewater, ecofriendly sorbents, advanced oxidation processes, membrane technology, and modeling in reverse osmosis optimization.

All of the accepted articles (Contribution 1-Contribution 13) provide recent advances in the most active wastewater treatment research fields. Rizwan Khan, Muhammad Ali Inam, Saba Zam Zam, Muhammad Akram, Sookyo Shin, and Ick Tae Yeom explored the removal of CuO nanoparticles from water by coagulation at different $\mathrm{pH}$ values and dissolved organic matter concentrations. The media pH significantly affected the coagulation efficiency of the nanoparticles. They observed that the simultaneous effect of coagulants and charge neutralization at $\mathrm{pH}$ 6-8 enhanced the removal of $\mathrm{CuO}$ nanoparticles. Their study suggests that coagulation is effective in removing the nanoparticles from complex matrices in a wide $\mathrm{pH}$ range. Their findings provide insight into the coagulation and dissolution behavior of $\mathrm{CuO}$ nanoparticles during the water treatment process (Contribution 1). In the field of activated sludge, Jin Xu, Peifang Wang, Yi Li, Lihua Niu, and Zhen Xing studied the effect of different organic carbon/ $\mathrm{N}$ ratii and dissolved oxygen (DO) levels and observed that the best treatment performance was achieved with a COD (Chemical Oxygen Demand)/N ratio of 7:1 or the DO levels of 2-2.5 mg/L. They observed evident microbial variance and changes in the richness and evenness of the microbial communities in the activated sludge. Their work provides valuable practical guidance for the operators of any wastewater treatment plant (Contribution 2). Research in constructed wetlands is continuously expanding and this Special Issue could attract different remarkable manuscripts. The sustainable application of constructed wetlands calls for the use of alternative materials to be used as substrates. Agro-forest wastes such as palm mulch can be a suitable alternative to gravel and sand. Thus, Marina Carrasco-Acosta, Pilar Garcia-Jimenez, José Alberto Herrera-Melián, Néstor Peñate-Castellano, and Argimiro Rivero-Rosales studied the effect of plants on relevant aspects of constructed wetland performance such as pollutant removal, substrate clogging, and bacterial community structure in organic-based vertical flow constructed wetlands. They observed that the presence of plants delayed the clogging of the reactors and reduced the biodiversity of Enterococci and E. coli as measured with terminal restriction fragment length polymorphism (T-RFLP) analysis (Contribution 3). Nowadays, water-energy management optimization is a key issue, but the threat of the climate change can make it imperative in the near future. Tuan-Viet Hoang, Pouya Ifaei, Kijeon Nam, Jouan Rashidi, Soonho Hwangbo, Jong-Min Oh, and Chang Kyoo Yoo proposed the optimization of a hybrid renewable energy system (HRES) coupled with a membrane bioreactor for the sustainable adaptation to climate change 
in Vietnam. The model-based HRES consisted of solar photovoltaic panels, wind turbines, and battery banks. The authors defined three scenarios, 101 sub-scenarios, and three management cases to optimize the system design. The results showed that the smallest environ-economic cost was obtained when $47 \%$ of the demand load of the membrane bioreactor was met using the HRES and the rest was supplied by the grid (Contribution 4). Another paper on constructed wetlands focused on the removal of heavy metals with the plant totora in the South American Altiplano region. Juan Blanco tested if the plant could be used in constructed wetlands treating mining wastewaters with high salinity and As and $\mathrm{Pb}$ concentrations. He compared the chemical composition of the leaves, rhizomes, and roots and observed that totora was a multi-hyperaccumulator for $\mathrm{As}, \mathrm{Fe}$, and Ni. These results, in addition with the plant's intrinsic high biomass production, slow decomposition, and usability as a raw material for local craftwork and industry, support the recommendation to use totora in wetlands to treat water polluted with heavy metals and/or with high salinity (Contribution 5). Rizwan Khan, Muhammad Ali Inam, Muhammad Mazhar Iqbal, Muhammad Shoaib, Du Ri Park, Kang Hoon Lee, Sookyo Shin, Sarfaraz Khan, and Ick Tae Yeom studied the influence of surfactant type in the removal of $\mathrm{ZnO}$ nanoparticles from natural waters by the coagulation-flocculation process. Anionic sodium dodecyl sulfate (SDS) and nonionic nonylphenol ethoxylate (NPEO) were employed as model surfactants. The adsorption of the nanoparticles, which was strongly $\mathrm{pH}$-dependent, was studied with Freundlich and Langmuir models. The formation of mono-bilayer patches onto the nanoparticles was suggested. The cooperation of charge neutralization and adsorptive micellar flocculation might explain the coagulation mechanism. This study provides new insight into the behavior of $\mathrm{ZnO}$ nanoparticles and surfactants in water treatment processes (Contribution 6). Nitrogen and phosphorus play a key role in food production but their environmental impact can be devastating when they are discharged in the natural watercourses. Jan Peter Van der Hoek, Rogier Duijff, and Otto Reinstra studied nitrogen recovery from wastewater. The current $\mathrm{N}$-based fertilizers have many drawbacks since energy requirements are high and in the wastewater treatment, $\mathrm{N}$ is lost to the atmosphere as $\mathrm{N}_{2}$. The authors selected technologies for $\mathrm{N}$ recovery from wastewater considering four criteria: sustainability, the potential to recover $\mathrm{N}$, the maturity of the technology, and the $\mathrm{N}$ concentration that can be handled by the technology. The most promising mature technologies that can be incorporated into existing wastewater treatment plants include struvite precipitation, the treatment of digester reject water by air stripping, vacuum membrane filtration, hydrophobic membrane filtration, and treatment of air from thermal sludge drying. Higher nitrogen recovery $(60 \%)$ could be achieved by separate urine collection, but a completely new infrastructure for wastewater collection and treatment would be necessary. Different technologies in parallel are required to reach sustainable solutions (Contribution 7). Shuang $\mathrm{Xu}$, Weiguang Yu, Sen Liu, Congying Xu, Jihui Li, and Yucang Zhang explored the adsorption of hexavalent chromium on a low cost banana pseudostem biochar. The biochar surface prepared at low temperature was rich in O-containing groups. The best results were obtained with the biochar prepared at $300{ }^{\circ} \mathrm{C}$ with a $125.44 \mathrm{mg} / \mathrm{g}$ maximum adsorption capacity. Pseudo-second-order kinetics and Langmuir model provided the best fit of the experimental data, indicating a monolayer chemi-adsorption. The adsorption of $\mathrm{Cr}(\mathrm{VI})$ was attributed to the reduction of $\mathrm{Cr}(\mathrm{VI})$ to $\mathrm{Cr}(\mathrm{III})$, ion exchange, and complexation (Contribution 8). Angela Gorgoglione and Vincenzo Torretta contributed with a revision of more than 120 constructed wetland (CWs) case studies with the goal of providing a tool for researchers and decision-makers considering using this green technology. The authors claim that although CWs are considered to be environmental-friendly and low cost, their sustainable management still remains a challenge. The study provides sustainable solutions for the performance and applications of CWs by means of the discussion of key aspects such as macrophyte species, media type, water level, hydraulic retention time, and hydraulic loading rate (Contribution 9). Additionally, very interesting research on the use of the green waste coffee silverskin in water treatment was performed by Angela Malara, Emilia Paone, Patrizia Frontera, Lucio Bonaccorsi, Giuseppe Panzera, and Francesco Mauriello. These authors assessed it for its suitability in the removal of $\mathrm{Cu}, \mathrm{Zn}$, and $\mathrm{Ni}$ divalent ions from water. The application of the Langmuir and Freundlich models demonstrated a monolayer-type adsorption. The results 
support the use of coffee silverskin as a new low cost adsorbent for metals in wastewater (Contribution 10). Reducing the effects of eutrophication on receiving waterbodies has many environmental, but also economic benefits. This way, Ben Morelli, Sarah Cashman, Xin (Cissy) Ma, Jay Garland, Jason Turgeon, Lauren Fillmore, Diana Bless, and Michael Nye applied life cycle and life cost assessments to determine the environmental benefits of upgrading a small community conventional activated sludge treatment process. The authors introduced biological nutrient removal, and enhanced primary settling and anaerobic digestion (AD) with co-digestion of high strength organic waste. The upgraded system significantly reduced eutrophication impact, global climate change potential, and cumulative energy demand relative to the legacy system (Contribution 11). Water treatment methods of different nature can also be combined to provide particularly suitable technologies. Hyun-Hee Jang, Gyu-Tae Seo and Dae-Woon Jeong proposed a combination of nanofiltration and ozone-hydrogen peroxide oxidation for the treatment of soy sauce waste. Currently, the application of ozone oxidation provides $34 \%$ color removal and $27 \%$ chemical oxygen demand reduction. The authors combined ozone with hydrogen peroxide and achieved color removal (52\%) and COD reduction (34 \%) with the optimized method. When nanofiltration was used as a pre-treatment, the method was remarkably improved since color removal was $98 \%$ and COD removal was $98 \%$. Thus, the $\mathrm{NF}-\mathrm{H}_{2} \mathrm{O}_{2} / \mathrm{O}_{3}$ process is one of the best methods to treat soy sauce waste (Contribution 12). Finally, with the goal of reducing the power consumption of the desalination industry in Kuwait, Bader S. Al-Anzi and Ashly Thomas developed a one-dimensional analytical model of pressure retarded osmosis in a parallel flow configuration. The model has been developed to "size" an osmotically-driven membrane process mass exchanger given the operating conditions and desired performance. The model has been used to determine mass transfer units as a function of mass flow rate ratio, recovery ratio, concentration factors, effectiveness, etc. The actual water permeation to the brine stream was related by the introduction of a new dimensionless dilution rate ratio and dilution rate, among others. A maximum power of 0.28 and $2.6 \mathrm{~kJ}$ can be produced by the system using seawater or treated wastewater effluent as the feed solution, respectively, which could help to reduce the power consumption of the desalination industry in Kuwait (Contribution 13).

\section{List of Contributions:}

1. Khan, R.; Inam, M.; Zam Zam, S.; Akram, M.; Shin, S.; Yeom, I. Coagulation and Dissolution of $\mathrm{CuO}$ Nanoparticles in the Presence of Dissolved Organic Matter under Different $\mathrm{pH}$ Values. Sustainability 2019, 11, 2825.

2. Xu, J.; Wang, P.; Li, Y.; Niu, L.; Xing, Z. Shifts in the Microbial Community of Activated Sludge with Different COD/N Ratios or Dissolved Oxygen Levels in Tibet, China. Sustainability 2019, 11, 2284.

3. Carrasco-Acosta, M.; García-Jiménez, P.; Herrera-Melián, J.; Peñate-Castellano, N.; Rivero-Rosales, A. The Effects of Plants on Pollutant Removal, Clogging, and Bacterial Community Structure in Palm Mulch-Based Vertical Flow Constructed Wetlands. Sustainability 2019, 11, 632.

4. Hoang, T.; Ifaei, P.; Nam, K.; Rashidi, J.; Hwangbo, S.; Oh, J.; Yoo, C. Optimal Management of a Hybrid Renewable Energy System Coupled with a Membrane Bioreactor Using Enviro-Economic and Power Pinch Analyses for Sustainable Climate Change Adaption. Sustainability 2019, 11, 66.

5. Blanco, J. Suitability of Totora (Schoenoplectus californicus (C.A. Mey.) Soják) for Its Use in Constructed Wetlands in Areas Polluted with Heavy Metals. Sustainability 2019, 11, 19.

6. Khan, R.; Inam, M.; Iqbal, M.; Shoaib, M.; Park, D.; Lee, K.; Shin, S.; Khan, S.; Yeom, I. Removal of ZnO Nanoparticles from Natural Waters by Coagulation-Flocculation Process: Influence of Surfactant Type on Aggregation, Dissolution and Colloidal Stability. Sustainability 2019, 11, 17.

7. Van der Hoek, J.; Duijff, R.; Reinstra, O. Nitrogen Recovery from Wastewater: Possibilities, Competition with Other Resources, and Adaptation Pathways. Sustainability 2018, 10, 4605.

8. Xu, S.; Yu, W.; Liu, S.; Xu, C.; Li, J.; Zhang, Y. Adsorption of Hexavalent Chromium Using Banana Pseudostem Biochar and Its Mechanism. Sustainability 2018, 10, 4250. 
9. Gorgoglione, A.; Torretta, V. Sustainable Management and Successful Application of Constructed Wetlands: A Critical Review. Sustainability 2018, 10, 3910.

10. Malara, A.; Paone, E.; Frontera, P.; Bonaccorsi, L.; Panzera, G.; Mauriello, F. Sustainable Exploitation of Coffee Silverskin in Water Remediation. Sustainability 2018, 10, 3547.

11. Morelli, B.; Cashman, S.; Ma, X.; Garland, J.; Turgeon, J.; Fillmore, L.; Bless, D.; Nye, M. Effect of Nutrient Removal and Resource Recovery on Life Cycle Cost and Environmental Impacts of a Small Scale Water Resource Recovery Facility. Sustainability 2018, 10, 3546.

12. Jang, H.; Seo, G.; Jeong, D. Advanced Oxidation Processes and Nanofiltration to Reduce the Color and Chemical Oxygen Demand of Waste Soy Sauce. Sustainability 2018, 10, 2929.

13. Al-Anzi, B.; Thomas, A. One-Dimensional Analytical Modeling of Pressure- Retarded Osmosis in a Parallel Flow Configuration for the Desalination Industry in the State of Kuwait. Sustainability 2018, 10, 1288.

Funding: This research was supported by the collaboration of the Spanish Ministry of Science, Innovation and Universities, the University of Las Palmas de Gran Canaria (Grant CGL2016-78442-C2-2-R, GOBESP2017-04 ULPGC) and the Programa Innova Canarias 2020.

Conflicts of Interest: The author declares no conflict of interest.

\section{References}

1. Nguvava, M.; Abiodun, B.J.; Otieno, F. Projecting drought characteristics over East African basins at specific global warming levels. Atmos. Res. 2019, 228, 41-54. [CrossRef]

2. Ziadi, A.; Hariga, N.T.; Tarhouni, J. Mineralization and pollution sources in the coastal aquifer of Lebna, Cap Bon, Tunisia. J. Afr. Earth Sci. 2019, 151, 391-402. [CrossRef]

3. Zhou, Y.; Wang, L.; Zhou, Y.; Mao, X. Eutrophication control strategies for highly anthropogenic influenced coastal waters. Sci. Total Environ. 2020, 705, 135760. [CrossRef] [PubMed]

4. Tayeb, A.; Chellali, M.R.; Hamou, A.; Debbah, S. Impact of urban and industrial effluents on the coastal marine environment in Oran, Algeria. Mar. Pollut. Bull. 2015, 98, 281-288. [CrossRef] [PubMed]

5. Diaz, R.J.; Rosenberg, R. Spreading dead zones and consequences for marine marine ecosystems. Science 2008, 321, 926-929. [CrossRef] [PubMed]

6. Chaukura, C.; Marais, S.S.; Moyo, W.; Mbali, N.; Thakalekoala, L.C.; Ingwani, T.; Mamba, B.B.; Jarvis, P.; Nkambule, T.T.I. Contemporary issues on the occurrence and removal of disinfection byproducts in drinking water-A review. J. Environ. Chem. Eng. 2020, 8, 103659. [CrossRef]

7. Álvarez-Ruiz, R.; Picó, Y. Analysis of emerging and related pollutants in aquatic biota. Trends Environ. Anal. Chem. 2020, 25, e00082. [CrossRef]

8. United Nations. Transforming Our World: The 2030 Agenda for Sustainable Development. 2015. Available online: http://www.un.org/ga/search/view_doc.asp?symbol=A/RES/70/1\&Lang=E (accessed on 3 March 2020).

9. Holkar, C.R.; Jadhav, A.J;; Pinjari, D.V.; Mahamuni, N.M.; Pandit, A.B. A critical review on textile wastewater treatments: Possible approaches. J. Environ. Manag. 2016, 182, 351-366. [CrossRef] [PubMed]

10. Guedes-Alonso, R.; Montesdeoca-Esponda, S.; Herrera-Melián, J.A.; Rodríguez-Rodríguez, R.; Ojeda-González, Z.; Landívar-Andrade, V.; Sosa-Ferrera, Z.; Santana-Rodríguez, J.J. Pharmaceutical and personal care product residues in a macrophyte pond-constructed wetland treating wastewater from a university campus: Presence, removal and ecological risk assessment. Sci. Total Environ. 2020, 703, 135596. [CrossRef] [PubMed]

(C) 2020 by the author. Licensee MDPI, Basel, Switzerland. This article is an open access article distributed under the terms and conditions of the Creative Commons Attribution (CC BY) license (http://creativecommons.org/licenses/by/4.0/). 